\title{
Faith and Unfaithfulness: Can Praying for Your Partner Reduce Infidelity?
}

\author{
Frank D. Fincham and Nathaniel M. Lambert \\ The Florida State University
}

\author{
Steven R. H. Beach \\ University of Georgia
}

\begin{abstract}
Because religion and/or spirituality is integral to the lives of a majority of the world population, we conducted 3 studies on the role of prayer in romantic relationships. Study $1(N=375)$ showed that prayer for the partner predicted lower levels of extradyadic romantic behavior over a 6-week period, over and beyond relationship satisfaction, and initial levels of extradyadic romantic behavior. In Study $2(N=83)$, we used an experimental design to show that participants assigned to pray for each day for 4 weeks engaged in lower levels of extradyadic romantic behavior during that time, compared with those who engaged in daily positive thoughts about the partner or a neutral activity. Perception of the relationship as sacred mediated the relation between experimentally manipulated prayer and later infidelity. Study 3 $(N=23)$ showed that objective observers rated participants who had been praying for their partner for 4 weeks as more committed to their romantic relationship than control participants. The implications of these results are then discussed.
\end{abstract}

Keywords: romantic relationships, prayer, infidelity

It is estimated that somewhere between $68.08 \%$ and $88.74 \%$ (4.54-5.92 billion) of the world's population profess some religious faith ("List of Religious Populations," 2010). Not surprisingly, belief in God and prayer are common behaviors in many societies. For example, survey research shows that in the United States, $92 \%$ of people believe in God ("U.S. Religious Landscape Survey," 2008) and that approximately 90\% pray at least occasionally (McCullough \& Larson, 1999). Many individuals use prayer spontaneously to cope with their problems (Barnes, PowellGriner, McFann, \& Nahin, 2004; McCaffrey, Eisenberg, Legedza, Davis, \& Phillips, 2004). Belief in a deity and the practice of prayer is also widespread in many other regions of the world (e.g., Middle East, Africa). Although spiritual activities such as prayer are therefore central to those we seek to understand, psychologists, along with other social scientists, have tended to keep "their distance from religion and spirituality" (Hill \& Pargament, 2003, p. 65), limiting their understanding of the impact of this behavior on potentially important outcomes. This is perhaps surprising, given the widespread practice of prayer. The primary objective of the current studies is to examine whether and how praying for one's partner may reduce infidelity.

There is some evidence that spiritual involvement or activity may have positive effects on some health and relationship outcomes. For example, in a recent review of clinical trials in which the effects of

This article was published Online First August 16, 2010.

Frank D. Fincham, and Nathaniel M. Lambert, Family Institute, The Florida State University; Steven R. H. Beach, Institute for Behavioral Research, University of Georgia.

This research was support in part by United States Department of Health and Human Services Grant 90FE0022 awarded to Frank D. Fincham.

Correspondence concerning this article should be addressed to Frank D. Fincham, Family Institute, The Florida State University, 120 Convocation Way, Tallahassee, FL 32306-1491. E-mail: ffincham@fsu.edu western religious activity and spirituality on health were examined, researchers concluded that religious activities benefit blood pressure, immune function, depression, and lower mortality (Townsend, Kladder, Ayele, \& Mulligan, 2002). There is also some evidence that religiosity is related to several positive outcomes in close relationships. Specifically, greater involvement in religious activities is related to higher levels of marital satisfaction (Mahoney et al., 1999) and marital stability, with three longitudinal studies indicating that religiousness predicts lower risk of divorce and divorce proneness and not vice versa (Booth, Johnson, Branaman, \& Sica, 1995; Clydesdale, 1997; Fergusson, Horwood, Shannon, 1984). Lambert and Dollahite (2006) found that religious participation helped couples deal with conflict in their marriage, and there is evidence that attendance at religious services decreases the likelihood of infidelity (Atkins \& Kessel, 2008). Finally, there is growing evidence linking religiosity to positive family outcomes in the African American community (e.g., Brodsky, 2000; Brody, Stoneman, \& Flor, 1996; Brody, Stoneman, Flor, \& McCrary, 1996).

Notwithstanding these findings, little is known about what specific aspects of religious behavior and spirituality are associated with positive health and relationship outcomes. It is difficult to determine whether specific religious behaviors caused these outcomes or whether the relation is due to self-selection. Several studies have reported self-selection bias to be problematic for making inferences from the current research findings on religiosity (e.g., Koenig, McCullough, \& Larson, 2001). Another pertinent limitation in making inferences from the current studies on religious influence is the plausibility of a third variable explanation. For example, although Townsend et al. (2002) found a link between religiosity and depression, it could be that it is actually the more expansive social networks found among religious participants (Ellison \& George, 1994; Joiner, Perez, \& Walker, 2002; Taylor, Chatters, \& Levin, 2004) that accounts for the association, rather than any specific religious behaviors per se. 
One obvious way to determine the true effect of religious/ spiritual behavior on variables of interest is through use of an experimental design. Of course, ethical and practical considerations preclude the random assignment of religion, thereby creating a puzzling dilemma for generating scientifically sound research in an area that affects a large majority of individuals in many societies. One possible solution to this dilemma is to experimentally manipulate a specific spiritual activity that is acceptable for a large segment of the population (e.g., prayer).

\section{Prayer: A Ubiquitous Spiritual Activity}

Prayer is an important aspect of religious worship, the frequency and content of which may be targeted for experimental manipulation. Prayer may be practiced individually, which can reduce the chance that common third variable problems such as religious social networks are operative. Prayer is a form of spiritual activity common to all the Abrahamic traditions (i.e., Judaism, Christianity, and Islam), and prayer has strong parallels in other religious traditions (e.g., Buddhism, Hinduism, Shinto). In light of its central role in so many religious traditions, prayer is a spiritual activity worthy of empirical investigation. However, despite its prevalence (McCullough \& Larson, 1999) and professed influence in people's lives (Barnes et al., 2004; McCaffrey et al., 2004), prayer has received remarkably little attention from researchers. In our research, we focus on colloquial, petitionary prayer, a form of prayer that invokes God's help in response to specific needs, using the individuals own language rather than a set or memorized prayer. Little effort has been made to provide a framework for understanding the impact of prayer that is informed by and grounded in an analysis of psychological and interpersonal processes.

\section{Prayer in the Context of Close Relationships}

Prayer has generally not been examined specifically or systematically in research on religiosity and relationships. Indeed, Parke (2001) went so far as to note that research on the more general topic of religion "is rarely represented in the scientific journals devoted to family issues" (p. 555). As a consequence, the influence of prayer on relationship outcomes remains largely unknown. We therefore turn to briefly consider why prayer may be important in the context of close relationships.

\section{Fincham and Beach's (1999) Goal Theory Perspective on Prayer}

Dudley and Kosinski (1990) have suggested that spiritual activities like prayer may help couples to more often "think of the needs of others, be more loving and forgiving, treat each other with respect, and resolve conflict" (p. 82). If correct, this suggests that there may be multiple psychological processes that connect prayer to relationship outcomes.

One possible mechanism involves motivational processes, specifically the goals pursued by relationship partners. Prayer can impact choice of goals and thereby the intentions and willingness to engage in particular behaviors that can either support or undermine relationship functioning. Fincham and Beach (1999) argued that these motivational processes are particularly consequential during attempts to reduce negative relationship transactions in the midst of relationship conflict as well as in the context of recovering from negative interactions that have already occurred. They hypothesize that during destructive interactions, couples commonly switch from the cooperative goals they profess and believe most of the time to emergent goals that are adversarial in nature. For example, rather than focusing on generating a couple-level solution to the problem at hand, partners locked in conflict may find themselves focused on getting their way-or at least focused on not losing the argument to the other partner. As a result, even couples who know how to facilitate the construction of cooperative solutions may not avail themselves of that knowledge. In the context of emergent goals, couples may engage in negative behaviors even when they know better. Wile (1993) captured this well in colloquial terms when he noted that "It is impossible to make I-statements when you are in the "hating my partner, wanting revenge, feeling stung and wanting to sting back' state of mind" (p. 2). Practitioners often work to help couples deal with such situations that can, if unchecked, rapidly escalate into long chains of increasingly negative behavior exchange that have been documented as the behavioral signature of a distressed relationship (see Fincham, 2003).

Building on this analysis, Beach, Fincham, Hurt, McNair, and Stanley (2008) offered a conceptual framework in which they argued that prayer for a relationship partner can function in ways that are consistent with the aims of traditional skills-based interventions with couples. That is, when implemented in the context of conflict, prayer can function as a time out, a commonly used procedure in skills-based couple interventions. In this context, prayer provides a time during which the partner can self-sooth and during which cooperative goals can regain their dominance, replacing revenge-oriented or competition-oriented motives. Moreover, praying for the partner connects the praying person to their partner vis-à-vis the deity. In this way, prayer serves to prime or reinforce couple identity. Finally, colloquial prayer to a deity has the added advantage of providing what can be considered (the ultimate form of) social support. There is some empirical evidence consistent with this analysis because it implicates prayer as possibly altering couple's goals, thereby ameliorating unproductive conflict responses. Specifically, couples reported that praying during times of conflict deescalated their negativity, contempt, and hostility; enhanced relationship and partner orientation; and encouraged individual and couple responsibility for reconciliation and problem solving (Butler, Stout, \& Gardner, 2002).

Although Beach et al. (2008) presented the above theoretical perspective in the context of couple conflict to demonstrate its potential as an intervention, the rationale supporting it is easily extended to handle approach-approach conflicts (e.g., conflict between temptation and fidelity) that may be consequential for relationship well-being, particularly relationship well-being in young, developing relationships in which external constraints may be less well-developed. That is, it can be argued that regular practice of intercessory prayer for the partner will serve to keep positive relationship goals salient and make it more likely that partners choose not to give into temptations that could be hurtful to their relationship partner (e.g., extra dyadic romantic involvement). Specifically, prayer for the partner may help make the 
partner's well-being a salient goal even in the context of other potentially distracting opportunities for extra dyadic involvement.

\section{Prayer and Perceived Sanctification}

One cognitive schema that may reflect greater salience of the partner and the relationship is perceiving one's relationship as holy and sacred. Mahoney and colleagues (1999) introduced and tested the idea that coming to perceive something as being sacred has important implications for behavior. They called this process "sanctification" and defined it as a process by which secular aspects of life become perceived as having spiritual significance and character (Mahoney, Pargament, Murray-Swank, \& MurraySwank, 2003). By juxtaposing partner and deity in the same context, praying specifically for the well-being of a partner should lead to increased perceptions of the relationship as being holy and sacred. For example if John petitions a deity to help Jessica overcome a particular challenge in her life or to help make their relationship stronger, his relationship with Jessica will be associated with the deity, making the deity a third member of the partnership.

Lambert and Dollahite (2008) invoked a common biblical phrase to describe the linking of partners with God as a "threefold cord" ("a threefold cord is not quickly broken"; see Ecclesiastes 4:12, English Standard Version). Couples in their study reported that including God in their marriage enhanced and stabilized marital commitment. In this same way, including God in a relationship as a threefold cord through praying for one's partner should imbue the relationship with perceived sacredness.

\section{Sanctification and Relationship Outcomes}

The idea of sanctification has been applied to both marital and college romantic relationship outcomes. Mahoney and colleagues (1999) found that perception of marriage as holy and sacred was related to greater global marital adjustment, more perceived benefits from marriage, less marital conflict, fewer communication problems, and more verbal collaboration for husbands and wives. Dollahite and Lambert (2007) found that perception of their marriage as being sacred enhanced couples' marital quality and fidelity. When young adult college students perceived their sexual relationships as sacred, they reported increased sexual satisfaction and increased frequency of sexual behavior with their primary sex partner (Mahoney et al., 2005).

We propose that having a stronger perception of a sanctified relationship should motivate individuals to protect and preserve their relationships by being faithful. This is consistent with Pargament and Mahoney's (2005) argument that because people invest a great deal of time and energy in pursuit of sacred matters, they will go to great lengths to protect and preserve that which they perceive to be sacred (Pargament \& Mahoney, 2005). One example of the influence of such a mindset on practical outcomes is a finding that participants who defined their work as a calling reported missing fewer days than those who defined it as a job or a career (Wrzesniewski, McCauley, Rozin, \& Schwartz, 1997). Also, Mahoney et al., (2005) reported that college students who perceived their bodies as sacred placed a higher priority on daily physical exercise. We therefore hypothesize that praying for one's romantic partner will be an important predictor of perceiving one's relationship as sanctified and that those who perceive their relationship as holy and sacred will be more likely to protect it, as reflected in less infidelity. Prior work by Fincham, Beach, Lambert, Stillman, and Braithwaite (2008) indicated that petitionary prayer is related to higher levels of relationship satisfaction, suggesting at least some generalization of beneficial effects. However, this association does not show that prayer for the partner protects against infidelity, an issue addressed in the current studies. We now turn to consider our primary outcome variable_-infidelity-in more detail.

\section{Alternatives to the Current Partner: Infidelity}

Infidelity is widespread in both dating and marital relationships (e.g., Wiederman, 1997; Wiederman \& Hurd, 1999). It can be argued that from an evolutionary perspective, being unfaithful while in a dating relationship may sometimes represent an effective mate selection strategy and a reasonable "insurance policy" against future relationship dissolution. Specifically, short-term mating behaviors such as infidelity allow individuals to assess prospective long-term mates (Buss \& Schmitt, 1993), refine longterm mate preferences (Greiling \& Buss, 2000), or even find a better mate (Symons, 1979). Nonetheless, even in dating contexts, infidelity can do serious damage to both the relationship and the individual partners; infidelity represents a flagrant violation of the rules or role expectations of most romantic relationships (Jones, Moore, Schratter, \& Negel, 2001) and is associated with considerable hurt when it occurs (Allen et al., 2005). Its importance is further emphasized by the fact that "dating behaviors may lead to the establishment of behavioral patterns maintained in marriage" (Drigotas, Safstrom, \& Gentilia, 1999, p. 510). Finally, extra dyadic involvement may also increase the transmission of physical illness via sexually transmitted infections and so has the potential to be of interest for reasons relating to public health.

\section{Current Studies and Hypotheses}

Our goal in the present research was to increase understanding of the role of prayer in romantic relationships by exploring its relation to extradyadic behavior. To accomplish this goal, we conducted three studies. In Study 1, we investigated whether praying for the partner is associated with lower levels of infidelity (greater avoidance of infidelity) over time. We hypothesized that prayer would be negatively associated with extradyadic romantic behavior (i.e., infidelity). In Study 2, we built on Study 1 by examining the impact of prayer on infidelity with an experimental design. We also tested a mechanism that might account for the effects of prayer, namely, perception of a sanctified relationship. We hypothesized that participants randomly assigned to pray each day for the partner over a 4-week period would show lower levels of extradyadic romantic behavior at the end of that period than would participants assigned to pray in general, to focus on positive partner qualities, or to a neutral activity. Importantly, Study 2 provides an undirected prayer condition to control for possible nonspecific effects of any form of prayer, such as priming a secure attachment (to God) or invoking a moral observing agent (by praying to a deity). We also hypothesized that perceiving the 
relationship as sacred would mediate the relation between prayer and extradyadic behavior. We also included a strictly behavioral measure of infidelity to ensure that prayer did not function simply to decrease report of immoral thoughts. Study 3 goes beyond the limitations of self-report data by examining the ratings of objective observers about the commitment level of those assigned to the prayer intervention. We hypothesized that participants who had prayed for their partner for 4 weeks would be rated as more committed to their romantic partners than would control participants.

\section{Study 1}

Our goal in Study 1 was to investigate whether prayer for the partner would influence willingness to engage in extradyadic romantic behavior that might produce hurt for the partner (e.g., infidelity). The value of prospectively predicting infidelity is emphasized by the criticism leveled at studies of infidelity; namely, much of this research involves past reports of infidelity, and data are therefore subject to motivated bias in participant reports (Drigotas et al., 1999).

\section{Method}

Participants and procedure. The study included 375 undergraduates (320 female) from a large public university situated in a semiurban setting in the Southeast who participated in the study for partial course credit. Participants ranged in age from 17 years to 29 years, with a median age of 19 years, and reported being in a romantic relationship. Participants completed all measures relevant to the current study midway through the academic semester and then again 6 weeks later.

Measures.

Prayer for partner. To measure prayer for partner we used a 4-item measure that included items such as, "I pray for the well being of my romantic partner," and "I pray that good things will happen for my partner." Participants indicated the frequency with which they engaged in the behavior described by each item on a 5 point scale ranging from 1 (never) to 5 (very frequently). Scores were summed such that larger scores indicated greater frequency of prayer for the partner. Coefficient alpha for Time 1 prayer for partner was .96.

Infidelity. At Time 1 and Time 2, participants completed a measure that assessed whether they engaged in four extradyadic activities in the past month with someone other than their specified romantic partner (kissing, sexual intimacy without intercourse, and sexual intercourse). Responses were yes $=1$ or no $=0$ and were summed so that higher scores reflected higher levels of infidelity.

Relationship satisfaction. Starting with 180 items previously used to assess relationship satisfaction, Funk and Rogge (2007) conducted an item response theory analysis to develop a 4-item measure of relationship satisfaction with optimized psychometric properties. Sample items are "How rewarding is your relationship with your partner?" (answered on a 6 point scale ranging from not at all to extremely ) and "I have a warm and comfortable relationship with my partner" (answered on a 6 point scale ranging from not at all true to very true). Their measure correlates .87 with the widely used Dyadic Adjustment Scale and - .79 with the Ineffective Arguing Inventory. In the current sample, the alpha was .93.

\section{Results}

Table 1 provides the correlations among the variables as well as their means and standard deviations. We tested our hypotheses using structural equations modeling with full information maximum likelihood estimation (FIML). FIML computes maximum likelihood estimates and standard errors for missing data by taking into account all of the data in the structural model. This procedure provides efficient estimation of statistical parameters from incomplete data and thus allows retention of the complete sample for all analyses (Little \& Rubin, 1987; Rubin, 1976; Schafer, 1997). Observed variables were used to test the model.

When predicting infidelity, it is important to take into account empirical evidence showing that relationship satisfaction is a key predictor of infidelity (e.g., Atkins, Baucom, \& Jacobson, 2001; Prins, Buunk, \& Van Yerpen, 1993). To examine our hypothesis that prayer for the partner would predict later infidelity over and beyond baseline infidelity and relationship satisfaction, we examined a cross-lagged stability model using structural equations modeling. As hypothesized, the cross-lagged relation from Time 1 prayer for partner to Time 2 infidelity yielded a significant parameter estimate $(\beta=-.11, p<.05)$, even when controlling for baseline infidelity and relationship satisfaction (for full results see Figure 1). Given that the relation between Time 1 prayer and Time 2 prayer was more stable $(\beta=.89, p<.05)$ than that of Time 1 infidelity with Time 2 infidelity $(\beta=.58, p<.05)$, we reran the model constraining the stability coefficients to be equal to ensure that this discrepancy was not responsible for our findings. The effect of Time 1 prayer on Time 2 infidelity remained significant with these constraints $(\beta=-.09, p<.05)$. To ensure that the effect was not dependent on controlling for relationship satisfaction, we tested the relation between Time 1 prayer and Time 2 infidelity, controlling for Time 1 infidelity only, and found that prayer for partner significantly predicted infidelity $(\beta=-.14, p<$ $.01)$. Finally, we tested the effect of sex, relationship length, relationship status, and ethnicity and found that none of these variables significantly altered the effect of praying for partner on infidelity, nor were there any interaction effects between these variables and praying for one's partner.

\section{Discussion}

Support was obtained for our hypothesis that prayer for the partner would be related to lower levels of infidelity over time. It

Table 1

Correlations, Means, and Standard Deviations for Variable in Study 1

\begin{tabular}{lcccc}
\hline \multicolumn{1}{c}{ Variables } & 1 & 2 & 3 & 4 \\
\hline 1. T1 prayer for partner & - & & & \\
2. T2 prayer for partner & .88 & - & & \\
3. T1 infidelity & -.09 & -.10 & - & \\
4. T2 infidelity & -.16 & -.18 & .60 & - \\
$M$ & 2.80 & 2.79 & 1.57 & 1.60 \\
$S D$ & 1.18 & 1.14 & 0.83 & 0.89 \\
Range & $1-5$ & $1-5$ & $1-3$ & $1-3$ \\
\hline
\end{tabular}

Note. $\quad N=375$. All values were significantly correlated at $p<.01 . \mathrm{T}=$ time. 


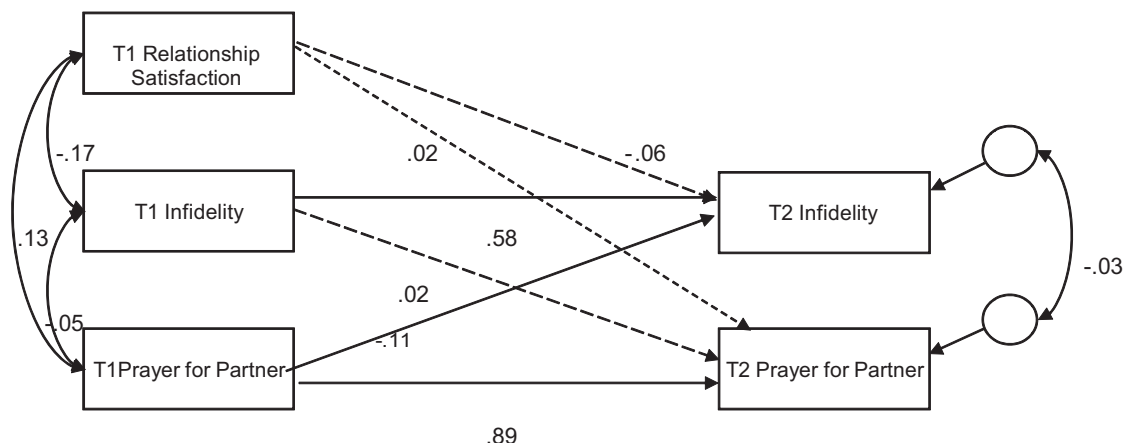

Figure 1. Cross-lagged stability model of prayer and infidelity in Study $1(N=375)$. The dotted line indicates path was not significant. $\mathrm{T}=$ time.

is notable that this finding emerged even though we controlled for relationship satisfaction. In fact, given past research on the association between relationship satisfaction and infidelity, it is striking that prayer for partner was a stronger predictor of later infidelity than was initial relationship satisfaction. Study 1 demonstrates a prospective relation between prayer and the outcome of interest, even while ruling out a rival, third variable explanation-relationship satisfaction.

The results of the current study demonstrate that there was a significant relation between earlier prayer and later infidelity. However, despite establishing temporal precedence with a prospective design, these data are correlational in nature and experimental data are required to more fully examine the direction of this relationship. In essence, a causal relation between prayer for partner and infidelity cannot be confidently inferred in the absence of experimental data. This was the primary objective of Study 2 .

Also, it is unclear whether specifically praying for a relationship partner has a different effect than prayer of any type on level of infidelity. In addition, it could be that simply thinking about the well-being of a partner or about the partner's positive traits during a prayer led to lower infidelity. In Study 2, we sought to rule out such alternative hypotheses through experimental controls. Specifically, we sought to determine the mechanism that might account for the relation between praying for a partner and infidelity and rule out plausible alternative hypotheses.

\section{Study 2}

Study 1 was noteworthy for moving beyond the simple demonstration of a concurrent association between prayer for the partner and infidelity. By introducing a temporal dimension, a stronger basis for making causal inferences exists, as it is widely accepted that cause precedes effect. Study 2 builds on Study 1 by introducing a longitudinal component and by providing experimental data on the link between prayer for the partner and infidelity. Participants were randomly assigned to a prayer for partner condition and to three different control conditions. The control conditions are designed to rule out plausible rival explanations for the effect of partner-focused prayer (i.e., repeated measurement, priming of nonspecific process through prayer, or increasing frequency of positive thoughts about the partner). We hypothesized that participants assigned to pray for their partner would report lower levels of infidelity than those assigned to the control conditions.

\section{Method}

Participants. The study included 83 undergraduates $(74 \mathrm{fe}-$ male) from a large public university situated in a semiurban setting in the Southeast who participated in the study for extra credit Participants ranged in age from 18 years to 34 years, with a median age of 19 years. Participants were invited to participate based on whether they (a) were currently involved in a romantic relationship and (b) reported that they engaged in at least a minimal level of prayer.

\section{Measures.}

Infidelity (thoughts and acts). To measure infidelity we used a nine-item infidelity scale designed for young adult dating relationships that measures both emotional and physical infidelity (Drigotas et al., 1999). This scale was chosen because of its sensitivity to the issue of social desirability. Specifically, the scale was developed to provide "a scale that could capture this behavior in such a manner that participants would be likely both to divulge information and to do so honestly" (Drigotas et al., 1999, p. 512). Participants were instructed to think of a person that they were most attracted to besides their partner. They were then asked nine questions about their level of attraction (e.g., "How attractive did you find this person?") arousal (e.g., "How much arousal did you feel in their presence?"), emotional engagement (e.g., "How emotionally intimate were you with this person?), and physical involvement (e.g., "How physically intimate were you with this person?"). The items were summed and coded such that higher scores indicated higher infidelity. The alpha for this measure in the current sample was .96 at Time 1 and .96 at Time 2 .

Infidelity acts. To ensure that praying for partner was not simply leading to report of fewer immoral thoughts, we also looked separately at reports of behavior. These comprised two items from the Drigotas et al. (1999) measure in which participants identified a person for whom they felt attracted. Participants were asked, "How emotionally intimate were you with this person?" and "How physically intimate were you with this person?" These items correlated at $r=.77$ at Time 1 and .74 at Time 2 .

Perception of a sanctified relationship. To assess perception of a sanctified relationship we used the two items recommended by A. Mahoney (personal communication, October 21, 2005; "My relationship with my partner is holy and sacred," and "I sense God's presence in my relationship with my partner") that were modified from her earlier measure (Mahoney et al., 1999). Items 
were coded such that higher levels of agreement indicated higher perceived sanctification. The items correlated at $r=.72$ at Time 1 and $r=.79$ at Time 2 .

Procedure. All participants completed a battery of measures that included those relevant to the current study. Then, participants were randomly assigned to one of four conditions and were instructed that they would need to complete their assigned activity every day for 4 weeks and keep a log of how many minutes they engaged in their activity each day. Participants were also required to $\log$ on to an online journal twice a week to report their log and provide written descriptions about their assigned activity. The assigned activity lasted 4 weeks.

Prayer for partner condition. This was the experimental condition, and those assigned to the prayer for partner condition were given the following instructions:

"Over the next 4 weeks we would like you to set aside at least one time each day to pray for the well-being of your partner. Keep track of how much time you spend doing this, as we will ask you to report it for each day." To help participants understand the type of prayer we had intended for them to pray, we provided them with an example prayer and requested that they generate their own prayer and report what they prayed about during each online session. The following is an example of instructions given to participants in a typical online session.

Please read the example prayer below to get an idea of the type of prayer we would like you to pray on behalf of your partner: "Dear Lord, thank you for all the things that are going well in my life and in my relationship. Please continue to protect and guide my partner, providing strength and direction every day. I know you are the source of all good things. Please bring those good things to my partner and make me a blessing in my partner's life. Amen." Now, please generate your own prayer in your own words on behalf of the well-being of your romantic partner, and in the space below, write a short description about what you prayed for.

Neutral condition (activity control). The objective of this condition was to ensure that the procedure of completing a daily activity and reporting about it twice a week was not responsible for posttest differences in infidelity.

Over the next 4 weeks, we would like you to please set aside at least one time each day to think about what you have done that day. Keep track of how much time you spend doing this, as we will ask you to report it for each day.

During each online session participants in this condition were asked to "Please write a summary of your activities over the past 3 days."

Undirected prayer condition. The purpose of this control condition was to examine the hypothesis that posttest differences in infidelity were due to increased frequency of prayer, priming a secure attachment figure, or to priming an external audience (God) thereby decreasing negative behavior. We hypothesized that praying specifically for the well-being of one's partner would uniquely contribute to the dependent variables above and beyond typical prayer. Those assigned to this condition were given the following instructions:

Over the next 4 weeks, please set aside at least one time each day to pray. Keep track of how much time you spend doing this, as we will ask you to report it for each day.
During each online session we asked them to "Please generate your own prayer in your own words on anything you'd like to pray about" and then "In a paragraph below, please describe your prayer."

Partner positive condition. Given that we requested participants in the prayer for partner condition to pray for positive things for their partners, the goal of this control condition was to examine the hypothesis that frequency of positive thoughts toward the partner accounted for group differences at follow up (Tesser et al., 1995). Participants in this condition were given the following instructions:

Over the next 4 weeks, please set aside at least one time each day to think positive thoughts about your partner. Keep track of how much time you spend doing this, as we will ask you to report it for each day.

During each online session we gave the following instructions:

We would like you to spend time thinking about your partner's positive qualities. Think of the things about your partner that you really like. These could be personality traits, or they could be things that your partner does. You can choose to focus on one or two things, or you can choose to identify and think about many things. The choice is yours. The important thing is that you keep in mind positive things about your partner while online today. In the space below, please write some of the positive things that you identified about your partner.

\section{Results}

Infidelity. Analysis of covariance (ANCOVA) with experimental group serving as a between-subjects factor and initial levels of infidelity serving as a covariate revealed a significant main effect for condition, $F(3,78)=3.19, p<.05$, $\eta_{\mathrm{p}}^{2}=.10$. Planned comparisons revealed that participants in the prayer for partner condition reported significantly lower infidelity scores $(M=2.44$, $S D=1.04)$ than did those in the neutral condition $(M=3.91$, $S D=2.16), F(1,78)=7.61, p<.01, d=.87$, and the positive thoughts about partner condition $(M=3.90, S D=2.37), F(1$, 78) $=6.70, p=.01, d=.80$, but not those in the undirected prayer condition $(M=3.19, S D=2.11), F(1,78)=2.02, p=.16, d=$ .45. However, those in the undirected prayer condition did not significantly differ from the other two conditions ( $p s>.05, n s$ ). All the means reported in this and subsequent analyses were adjusted for the covariates (see Table 2).

Given that the infidelity scores of those in the undirected prayer condition did not differ significantly from those in the prayer for partner condition, we conducted further analyses to examine whether praying for the partner was driving the effect on infidelity. In particular, the potential for overlap in the content of prayers between the undirected and prayer for partner conditions suggested the possibility that some in the undirected condition chose to pray for their partner. To explore this possibility, we examined participants' descriptions of their prayers in the undirected prayer condition and excluded 4 participants who prayed for the well-being of their partner at both time points. We redid the analyses without these participants and again found a significant overall main effect, $F(3,74)=3.23, p<.05$, $\eta_{\mathrm{p}}^{2}=.12$. Planned comparisons revealed that participants in the prayer for partner condition reported significantly lower infidelity scores $(M=2.52, S D=1.04)$ than did those in the undirected prayer condition $(M=3.62, S D=2.06), F(1,74)=4.02, p<.05, d=.67$. 
Table 2

Adjusted Means and Standard Deviations for Each Experimental Condition in Study 2

\begin{tabular}{lcccc}
\hline & \multicolumn{4}{c}{ Experimental condition } \\
\cline { 2 - 5 } & $\begin{array}{c}\text { Prayer for } \\
\text { partner }\end{array}$ & $\begin{array}{c}\text { Undirected } \\
\text { prayer }\end{array}$ & $\begin{array}{c}\text { Partner } \\
\text { positive }\end{array}$ & Neutral \\
\hline Dependent variable & & & & \\
T2 infidelity & 2.44 & 3.19 & 3.90 & 3.91 \\
$\quad M$ & 1.04 & 2.11 & 2.37 & 2.16 \\
$\quad S D$ & 1.72 & 2.68 & 3.06 & 3.29 \\
Infidelity (acts) & 1.01 & 2.38 & 2.35 & 2.70 \\
$M$ & & & & \\
$S D$ & 3.67 & 3.41 & 2.81 & 3.26 \\
Sanctified relationships & 1.02 & 0.96 & 0.96 & 0.89 \\
$\quad M$ & & & & \\
$S D$ &
\end{tabular}

Note. $\quad N=83$. Prayer for partner $n=22$; undirected prayer $n=22$; neutral $n=20 . \mathrm{T}=$ time.

Comparisons with means in other conditions continued to be significant in the neutral condition $(M=3.95, S D=2.16), F(1,74)=7.58$, $p<.01, d=.84$, and the positive thoughts about partner condition $(M=3.90, S D=2.37), F(1,74)=6.28, p=.01, d=.75$. This analysis suggests that praying for the partner uniquely affects extradyadic thoughts and actions and that it occurs without experimental instruction for some participants, creating the potential for confounding of experimental conditions unless the contents of prayers are directly assessed.

Infidelity acts. To ensure that praying for the partner was affecting actual behavior rather than just moral thoughts or intentions, we examined only infidelity behaviors to determine whether the effect of praying for the partner would persist, using only the items "How emotionally intimate were you with this person?" and "How physically intimate were you with this person?" Analysis of covariance (ANCOVA) with experimental group serving as a between-subjects factor, and initial levels of infidelity acts serving as covariates revealed a significant main effect for condition, $F(3$, $78)=2.65, p=.05, \eta_{\mathrm{p}}^{2}=.09$. Planned comparisons revealed that participants in the prayer for partner condition reported significantly lower infidelity act scores $(M=1.72, S D=1.01)$ than did those in the neutral condition $(M=3.06, S D=2.35), F(1,78)=$ 4.74, $p<.01, d=.74$, and those in the positive thoughts about partner condition $(M=3.29, S D=2.70), F(1,78)=6.07, p=$ $.02, d=.77$, but were only marginally different than those in the undirected prayer condition $(M=2.68, S D=2.38), F(1,78)=$ 2.57, $p=.11, d=.52$. However, those in the undirected prayer condition did not significantly differ from the other two conditions, $p s<.05, n s$. All the means reported in this analysis were adjusted for covariates.

As for the prior analyses, because 4 participants in the undirected prayer condition consistently prayed for their partners, we redid this analysis without these participants and again found a marginally significant main effect, $F(3,74)=2.59, p=.06, \eta_{\mathrm{p}}^{2}=$ .10. Planned comparisons revealed that participants in the prayer for partner condition reported significantly lower infidelity scores $(M=1.74, S D=1.01)$ than did those in the undirected prayer condition $(M=3.03, S D=2.47), F(1,74)=6.15, p<.05, d=$ .68. Again, significance of comparison with means for other con- ditions was unchanged in the neutral condition $(M=3.08, S D=$ $2.35), F(1,74)=5.40, p<.01, d=.74$, and the positive thoughts about partner condition $(M=3.25, S D=2.70), F(1,77)=6.07$, $p<.05, d=.74$. This again demonstrates that praying for the partner seems to have a unique effect on extradyadic behavior.

Relationship sanctification effect. Controlling for initial levels of sanctification, we found a significant main effect for condition, $F(3,77)=2.93, p<.05, \eta_{\mathrm{p}}^{2}=.10$. Planned comparisons revealed that those in the prayer for partner condition reported significantly greater sanctification scores $(M=3.67, S D=1.02)$ than did those in the positive thought about partner condition $(M=$ $2.81, S D=0.96), F(1,77)=8.42, p<.01, d=.87$, but the difference only approached significance with the neutral condition $(M=3.26, S D=0.89), F(1,77)=2.14, p=.15, d=.43$, and was not significantly greater than scores in the undirected prayer condition $(M=3.41, S D=0.96), F(1,77)=0.99, p>.05, d=$ .26. No other contrasts were significant.

Perception of sanctified relationship as a mediator. The experimental condition was dummy coded such that prayer for partner equals 1 , and the three control conditions were coded as 0 ; this was entered as the independent variable with Time 2 infidelity (all 9 items) as the dependent variable, Time 2 sanctification as the mediator, and Time 1 infidelity serving as a covariate. We tested whether perception of sanctified relationship would mediate the relation between praying for partner (experimental condition) and Time 2 infidelity. The independent variable, experimental condition, was significantly related to the mediator, relationship sanctification ( $\beta=.27, p=.01$ ). The mediator, relationship sanctification, was significantly related to the dependent variable, Time 2 infidelity $(\beta=-.25, p<.01)$, controlling for experimental condition.

To test whether perception of one's relationship as being holy and sacred mediated the relation between praying for one's partner and infidelity, we conducted a bootstrapping analysis recommended by Preacher and Hayes (2008). Bootstrapping involves the repeated extraction of samples from the data set (in this case, 5,000 samples were taken) and the estimation of the indirect effect in each resampled data set. The totality of all the estimated indirect effects permits the construction of a $95 \%$ confidence interval for the effect size of each indirect effect. If the confidence interval for the indirect effect includes zero, this indicates a nonsignificant effect.

The $95 \%$ confidence interval for the current analysis of sanctified relationships as a mediator between condition and infidelity was -.38 to -.09 and did not include zero, indicating statistically significant mediation. We also tested whether perceived Time 2 sanctification would mediate between experimental condition and Time 2 infidelity acts (i.e., the 2 behavioral items). It did, as the $95 \%$ confidence interval did not, include zero $(-.19$ to -.01$){ }^{1}$

\section{Discussion}

The current study is among the first to provide experimental data on prayer and close relationships. Building on the suggestive finding of Study 1, the current study revealed that praying for the partner on a daily basis resulted in lower extradyadic thoughts and

\footnotetext{
${ }^{1}$ The results did not change when we excluded the 4 undirected prayer participants who consistently prayed for their partners.
} 
behavior, even in comparison with undirected prayer. This finding is not easily explained by the idea that the mechanism of action has to do with nonspecific aspects of prayer such as priming fidelity as a construct, priming secure attachment (Baldwin, 2007), or priming other nonspecific aspects of prayer such as the mere presence of an observing moral agent (Shariff \& Norenzayan, 2007) or a broader time perspective leading to enhanced awareness of relationship commitment (Stanley \& Markman, 1992). The contrast with undirected prayer was sharpened when we excluded the 4 participants in the undirected prayer condition who consistently prayed for their partner across both time points. With these participants removed, there was a significant difference in reported infidelity between participants assigned to the prayer for partner condition and participants assigned to the undirected prayer condition. In addition, those who prayed for benefits to accrue to their partner differed from both nonprayer control groups. It therefore appears that there is something about praying, especially about praying for the partner's well being, that is related to reduced infidelity in thought and action.

Furthermore, the current study also provides evidence that praying for the partner had an effect beyond simply reducing extradyadic thoughts. Indeed, analysis revealed that when exclusively examining extradyadic behavior, praying for the partner continued to uniquely predict such behavior. Finally, the current study provided evidence that the perception of having a sanctified relationship mediates the relation between praying for partner and infidelity.

One limitation of Studies 1 and 2, however, is that they rely on the participants' self-report of their extradyadic thoughts and behaviors, which does not preclude dissonance reduction or demand characteristics as potential alternative explanations. For example, perhaps when participants become aware of being in a condition in which they will pray, this awareness makes them more apt to respond in a way they think the experimenter may desire. We partially addressed the concern about self-report in Study 2 by examining reports of behavior separately from "softer" indices of infidelity. In addition, we partially addressed the concern about socially desirable responding by including an undirected prayer condition that should have produced similar impact on socially desirable responding. However, in Study 3, we more fully address this concern by moving beyond self-report data entirely.

\section{Study 3: Daily Journal and Objective Observer Report}

The previous studies describe a consistent pattern of results yet are somewhat limited because they used participants' self-reports concerning fidelity in the relationship. The limitations of selfreport methods have been extensively documented (e.g., see Stone et al., 2000) and include impression management, motivated distortion, and limits of self-awareness (Fincham \& Rogge, in press). The objective of this final study was to move beyond the limitations of self-report data and to test whether the effects of praying for the partner could be perceived by objective observers. This creates a challenge as our focal measure, infidelity, is known only to participants and is not subject to observation by others. However, commitment to the partner has logical connections to infidelity and is something that may be observed by objective raters.

\section{Method}

Participants. Twenty-three individuals from a large public university situated in a semiurban setting in the Southeast participated in the study for extra credit. They ranged in age from 18 years to 32 years, with a median age of 19 years, and they were instructed to answer all questions about their romantic partner. Only participants that reported being comfortable with prayer were invited to participate in the study, and all others were informed of an alternative extra credit opportunity. Participants completed the 4-item relationship satisfaction measure (Funk \& Rogge, 2007) from Study 1 ( $\alpha=.84)$ prior to random assignment to condition.

Procedure. After all participants completed pretest measures they were randomly assigned to one of two conditions and were instructed that they would need to complete their assigned activity every day and keep a log of how many minutes they engaged in their activity each day. Participants were also required to $\log$ on to an online journal twice a week to report their log and provide written descriptions about their assigned activity.

Prayer for partner condition. This was the experimental condition, and the 10 participants assigned to this condition were given the following instructions:

Over the next 4 weeks we would like you to set aside at least one time each day to pray for the well-being of your partner. Keep track of how much time you spend doing this, as we will ask you to report it for each day.

To help participants understand the type of prayer we had intended for them to pray, we provided them with a sample prayer and requested that they generate their own prayer and report what they prayed about during each online session.

Positive-thoughts condition. Given that we requested participants in the prayer condition to pray for positive things for their romantic partner, the goal of this control condition was to help rule out the alternative hypothesis that it was simply the frequency of positive thoughts people had toward their partner while they prayed that caused any between-groups differences on follow-up measures (cf. Tesser et al., 1995). The 13 participants assigned to this condition were given the following instructions:

Over the next 4 weeks, please set aside at least one time each day to think positive thoughts about your partner. Keep track of how much time you spend doing this, as we will ask you to report it for each day.

At the conclusion of the 4-week period, participants came into the laboratory with their romantic partner and engaged in a videotaped interaction. The question posed to the participants that was relevant to the current study was, "Please describe the short- or long-term future of your relationship with your partner." Their responses to this question were coded by a group of five trained research assistant coders, blind to study hypotheses and the condition to which the participant was assigned. After watching the participants' response to this question, the research assistants coded their response based on the question, "How would you rate the commitment that the participant demonstrated to the partner during this interaction?" on a scale from $(1=$ not at all committed to $7=$ extremely committed). The interrater reliability of the coders' responses to this question was high, with an alpha of .85 . 


\section{Results and Discussion}

We tested our hypothesis that praying for a close other every day for 4 weeks would affect participants' commitment as observed by objective raters blind to study hypotheses. Our hypothesis gained support as results revealed higher observer reports of commitment among those in the prayer for partner condition $(M=$ $5.25, S D=.86)$ than among those in the positive-thought condition $(M=4.61, S D=.90), F(1,35)=3.07, p<.10, \eta_{\mathrm{p}}^{2}=.13$, controlling for initial self-reported relationship satisfaction. These results suggest that the effect of praying for one's partner on one's commitment is apparent even to objective observers. The results of this study address the shortcomings of Studies 1 and 2 that relied on self-report data and provide further evidence for the effect of praying for a partner on infidelity and commitment. Finally, it should be noted that this finding falls short of conventional levels of significance but is nonetheless noteworthy, given the low power of the analysis and the effect size obtained.

\section{General Discussion}

The current series of studies provides evidence that prayer focused on requesting beneficial outcomes (blessings) for the partner is associated with decreased propensity to transgress against the partner by engaging in extradyadic romantic behavior. The longitudinal study controlled for a potential third variable and set the stage for an experimental examination of effects and rival hypotheses. In particular, the longitudinal design used in Study 1 established that the effect of prayer on infidelity was not merely an artifact of its association with overall relationship satisfaction. Likewise, the experimental design used in Study 2 ruled out plausible rival explanations involving passage of time or repeated measurement, as well as ruling out frequency of positive thoughts about the partner and nonspecific aspects of prayer. Study 3 used objective ratings and thereby addressed the limitations of selfreported data. Together, the set of studies suggests that prayer is an activity with the potential to produce change in important choice behaviors in dyadic relationships.

Infidelity is typically assumed to be strongly influenced by level of relationship satisfaction, suggesting that naturally occurring covariation between activities such as prayer for the partner and infidelity might be simply reflecting this third variable. For example, Prins et al. (1993) found that dissatisfaction was associated with increased desire for infidelity, whereas Glass and Wright (1985) found a negative correlation between relationship satisfaction and all types of infidelity (e.g., sexual, emotional, or combined). It is possible that the link with dissatisfaction may be particularly important for women's infidelity (Prins et al., 1993). However, in Study 1, we controlled for differences in relationship satisfaction, and in Study 2, we attempted to do so through randomization. In each case, prayer exerted effects despite controls for the potentially confounding effect of relationship satisfaction.

Given that general disapproval of infidelity is high (more than $90 \%$ of the general public agreed that it is always or almost always wrong, Smith, 1994), research on infidelity is plagued by the problem of socially desirable responding. Our studies attempted to deal with this issue by controlling for initial level of reported infidelity, as much of such tendencies would be picked up by this measure at Time 1. For example, if a person is willing to admit to infidelity at Time 1. they will likely admit to it at Time 2. Thus, even if some people do not report it, it would not affect our results as we examined the changes in infidelity over time. Likewise, the experimental design used in Study 2 should equalize such tendencies across condition through randomization. Given the nature of Study 3, we evaded socially desirable responding in this study.

The current studies also advance the theory of prayer's effect on relationships in three ways. First, they establish prayer as an independent source of influence on an important relationship behavior. Given the substantial number of people who say they engage in prayer, this rectifies an important oversight in the literature on close relationships. Second, the studies are consistent with Fincham and Beach's (1999) goal theory analysis of relationship conflict. Specifically, in this case, we tested whether praying for the partner had an effect on perceptions of having a sanctified relationship, and it did. This enhanced perspective of the relationship appears to have impacted participants' choice of goals for their relationship and thereby the intentions and willingness to engage in particular behaviors that can undermine relationship functioning were reduced and chosen less often, even if they were not less tempting or less salient as options. In this respect, prayer appears well poised for examination within accommodation paradigms (Rusbult et al. 1991), setting the stage for fruitful experimental elaboration of the impact of prayer on a range of relationship behaviors and outcomes. It should be noted, however, that undirected prayer sometimes results in participants praying for their partner, creating potential overlap with the experimental manipulation in the directed prayer condition. At the same time, when undirected prayer does not result in prayer for the partner, it does not have equivalent effects.

The current studies also suggest that for maximum impact on a particular class of behavior, prayer content should be focused on that class of behavior. This represents a potentially important practical insight, as well as a potentially important theoretical insight, and one that is analogous to what has been found in research on the relation between attitudes and behavior (see Ajzen, 2001). Specifically, prayer that is unfocused or focused on outcomes unrelated to the relationship or the partner cannot be anticipated to have the same effects on relationship outcomes as does prayer requesting beneficial outcomes for the partner. This implies that insights from social psychology can be fruitfully applied to research on prayer, perhaps providing ways to enhance the behavioral impact of prayer. At the same time, prayer represents an exciting context for the study of many social psychological processes and provides an opportunity to test competing theories. Additionally, because it is practiced widely, research on the implications of prayer has considerable practical significance.

\section{Limitations and Future Directions}

Notwithstanding its intriguing theoretical and practical implications, this set of research findings is limited by the use of student samples. It cannot be assumed that the findings will generalize to different kinds of relationships (e.g., marriage, same sex relationships) or to relationships in later adulthood. The practical implications of the findings are necessarily limited to persons who already believe in a supreme being and engage in prayer. Although it is an empirical question, it seems likely that prayer would not have similar effects for those who do not hold such beliefs and 
engage in such practices (e.g., atheists, agnostics). Finally, it cannot be concluded that all forms of prayer are beneficial because this research does not explore the potential adverse effects of prayer. It is possible that some forms of prayer, or prayer with certain foci, might be harmful for some relationship outcomes. For example, in some instances, prayer might be used to manipulate a partner or induce guilt. Alternatively, prayer may focus on the partner in a manner that increases blame and vilification directed toward the other. There is clearly a need to document the boundary conditions under which the type of petitionary prayer studied here has beneficial rather than negative effects. Furthermore, prayer may be partially responsible for keeping some individuals in a destructive relationship, which would be another plausible negative outcome of prayer.

We found that praying for one's partner increased participants' perception of having a sanctified relationship, which in turn decreased extradyadic thoughts and actions. An important direction for future research is to identify additional mechanisms relating prayer to relationship behaviors. The importance of future research on mechanisms is emphasized by the fact that some mediating outcomes, such as partner-positive goals, may have broad implications, but the sets of outcomes predicted to change may vary somewhat, depending on the nature of the mediators. Another possible mediator would be dissonance. To pray for the partner each day and then engage in extradyadic behavior undoubtedly would result in substantial dissonance, an unpleasant state that participants presumably seek to avoid. The behaviors implied by each potential mediator differ; commitment predicts change in relationship maintenance behavior; partner-positive goal priming predicts goal facilitation regardless of implications for relationship maintenance; dissonance predicts facilitation when failure to do so would highlight a discrepancy.

Similarly, beneficence should be directly assessed in future research on the impact of prayer. The goal theoretic perspective of Fincham and Beach (1999) suggests the associated hypothesis that prayer for beneficial outcomes for the partner may prime the goal of enhancing partner-positive outcomes. If so, this would be expected to generalize to a range of positive relationship behaviors including decreased infidelity.

Despite all the work that still needs to be done, it is no trivial achievement to demonstrate that prayer causally influences infidelity (and commitment) and that perception of the relationship as holy and sacred (sanctification) functions as the mechanism for this effect. Absent such data, emphasizing the importance of understanding the role of prayer in the lives of those we seek to understand and help, this human behavior would likely garner little attention.

\section{Conclusion}

In sum, the current studies set the stage for greater attention to prayer as a naturally occurring, high frequency behavior with potential implications for a range of relationship outcomes. It is amenable to investigation with well-established socialpsychological techniques and has strong potential to provide important insights in a range of self-regulatory and affective processes. Prayer is both an important behavior for study as well as potentially fertile ground for social psychological investigation of relationships. It is remarkable that to date it has remained so understudied in the area of close relationships and in psychology more generally.

\section{References}

Ajzen, I. (2001). Nature and operation of attitudes. Annual Review of Psychology, 52, 27-58.

Allen, E. S., Atkins, D. C., Baucom, D. H., Snyder, D. K., Gordon, K. C., \& Glass, S. P. (2005). Intrapersonal, interpersonal, and contextual factors in engaging in and responding to extramarital involvement. Clinical Psychology: Science and Practice, 12, 101-130.

Atkins, D. C., Baucom, D. H., \& Jacobson, N. S. (2001). Understanding infidelity: Correlates in a national random sample. Journal of Family Psychology, 15, 735-749.

Atkins, D. C., \& Kessel, D. E. (2008). Religiousness and infidelity: Attendance, but not faith and prayer, predict marital fidelity. Journal of Marriage and Family, 70, 407-418.

Baldwin, M. W. (2007). On priming security and insecurity. Psychological Inquiry, 18, 157-162.

Barnes, P. M., Powell-Griner, E., McFann, K., \& Nahin, R. L. (2004). Complementary and alternative medicine use among adults: United States, 2002. (CDC Advance Data No. 343). Retrieved from http:// www.cdc.gov/nchs/data/ad/ad343.pdf

Beach, S. R. H., Fincham, F. D., Hurt, T., McNair, L. M., \& Stanley, S. M. (2008). Prayer and marital intervention: A conceptual framework. Journal of Social and Clinical Psychology, 27, 693-710.

Booth, A., Johnson, D. R., Branaman, A., \& Sica, A. (1995). Belief and behavior: Does religion matter in today's marriage? Journal of Marriage and Family, 57, 661-671.

Brodsky, A. E. (2000). The role of religion in the lives of resilient, urban, African American, single mothers. Journal of Community Psychology, 28, 199-219.

Brody, G. H., Stoneman, Z., \& Flor, D. (1996). Parental religiosity, family processes, and youth competence in rural, two-parent African American families. Developmental psychology, 32, 696-706.

Brody, G. H., Stoneman, Z., Flor, D., \& McCrary, C. (1994). Religion's role in organizing family relationships: Family process in rural, twoparent African American families. Journal of Marriage and the Family, $56,878-888$.

Buss, D. M., \& Schmitt, D. P. (1993). Sexual strategies theory: An evolutionary perspective on human mating. Psychological Review, 100, 204-232.

Butler, M. H., Stout, J. A., \& Gardner, B. C. (2002). Prayer as a conflict resolution ritual: Clinical implications of religious couples' report of relationship softening, healing perspective, and change responsibility. American Journal of Family Therapy, 30, 19-37.

Clydesdale, T. T. (1997). Family behaviors among early U.S. baby boomers: Exploring the effects of religion and income change, 19651982. Social Forces, 722, 605-636.

Dollahite, D. C., \& Lambert, N. M. (2007). Forsaking all others: How religious involvement promotes marital fidelity in Christian, Jewish, and Muslim couples. Review of Religious Research, 48, 290-307.

Drigotas, S. M., Safstrom, C. A., \& Gentilia, T. (1999). An investment model prediction of dating infidelity. Journal of Personality and Social Psychology, 77, 509-524.

Dudley, M. G., \& Kosinski, F. A. (1990). Religiosity and marital satisfaction: A research note. Review of Religious Research, 32, 78-86.

Ellison, C. G., \& George, L. K. (1994). Religious involvement, social ties, and social support in a southeastern community. Journal for the Scientific Study of Religion, 33, 46-61.

Fergusson, D. M., Horwood, L. J., \& Shannon, F. T. (1984). A proportional hazards model of family breakdown. Journal of Marriage and the Family, 46, 539-549.

Fincham, F. D. (2003). Marital conflict: Correlates, structure and context. Current Directions in Psychological Science, 12, 23-27. 
Fincham, F. D., \& Beach, S. R. (1999). Marital conflict: Implications for working with couples. Annual Review of Psychology, 50, 47-77.

Fincham, F. D., Beach, S. R. H., Lambert, N., Stillman, T., \& Braithwaite, S. R. (2008). Spiritual behaviors and relationship satisfaction: A critical analysis of the role of prayer. Journal of Social and Clinical Psychology, $27,362-388$.

Fincham, F. D., \& Rogge, R. (in press). Understanding relationship quality: Theoretical challenges and new tools for assessment. Journal of Family Theory \& Review.

Funk, J. L., \& Rogge, R. D. (2007). Testing the ruler with item response theory: Increasing precision of measurement for relationship satisfaction with the Couples Satisfaction Index. Journal of Family Psychology, 21, 572-583.

Glass, S. P., \& Wright, T. L. (1985). Sex differences in type of extramarital involvement and marital dissatisfaction. Sex Roles, 12, 1101-1120.

Greiling, H., \& Buss, D. M. (2000). Women's sexual strategies: The hidden dimension of extra-pair mating. Personality and Individual Differences, 28, 929-963.

Hill, P. C., \& Pargament, K. I. (2003). Advances in the conceptualization and measurement of religion and spirituality: Implications for physical and mental health research. American Psychologist, 58, 64-74.

Joiner, T., Perez, M., \& Walker, R. (2002). Playing devil's advocate: Why not conclude that the relation of religiosity to mental health reduces to mundane mediators? Psychological Inquiry, 13, 214-216.

Jones, W. H., Moore, D. S., Schratter, A., \& Negel, L. A. (2001). Interpersonal transgressions and betrayals. In R. M. Kowalski (Ed.), Behaving badly: Aversive behaviors in interpersonal relationships (pp. 233256). Washington, DC: American Psychological Association.

Koenig, H. G., McCollough, M. E., \& Larson, D. B. (Eds.). (2001). Handbook of religion and health. New York, NY: Oxford University Press.

Lambert, N. M., \& Dollahite, D. C. (2006). How religiosity helps couples prevent, resolve, and overcome marital conflict. Family Relations, 55, $439-449$.

Lambert, N. M., \& Dollahite, D. C. (2008). The threefold cord: Marital commitment in religious couples. Journal of Family Issues, 23, 551576

List of Religious Populations. (2010). In Wikipedia. Retrieved January 4, 2010, from http://en.wikipedia.org/w/index.php?title=List_of_ religious_populations\&oldid $=335775267$

Little, R. J. A., \& Rubin, D. B. (1987). Statistical analysis with missing data. New York, NY: Wiley.

Mahoney, A., Carels, R., Pargament, K. I., Wachholtz, A., Edwards Leeper, L., Kaplar, M., \& Frutchey, R. (2005). The sanctification of the body and behavioral health patterns of college students. The International Journal for the Psychology of Religion, 15, 221-238.

Mahoney, A., Pargament, K. I., Jewell, T., Swank, A. B., Scott, E., Emery, E., \& Rye, M. (1999). Marriage and the spiritual realm: The role of proximal and distal religious constructs in marital functioning. Journal of Family Psychology, 13, 321-338.

Mahoney, A., Pargament, K. I., Murray-Swank, A., \& Murray-Swank, N. (2003). Religion and the sanctification of family relationships. Review of Religious Research, 44, 220-236.

McCaffrey, A. M., Eisenberg, D. M., Legedza, A. T. R., Davis, R. B., \& Phillips, R. S. (2004). Prayer for health concerns: Results of a national survey on prevalence and patterns of use. Archives of Internal Medicine, $164,858-862$.

McCullough, M. E., \& Larson, D. B. (1999). Prayer. In W. R. Miller (Ed.), Integrating spirituality into treatment: Resources for practitioners (pp. 85-110). Washington, DC: American Psychological Association.
Pargament, K. I., \& Mahoney, A. M. (2005). Sacred matters: Sanctification as a phenomena of interest for the psychology of religion. The International Journal for the Psychology of Religion, 15, 179-199.

Parke, R. (2001). Introduction to the special section on families and religion: A call for a recommitment by researchers, practitioners, and policymakers. Journal of Family Psychology, 15, 555-558.

Preacher, K. J., \& Hayes, A. F. (2008). Asymptotic and resampling strategies for assessing and comparing indirect effects in multiple mediator models. Behavior Research Methods, 40, 879-891.

Prins, K. S., Buunk, B. P., \& Van Yperen, N. W. (1993). Equity, normative disapproval, and extramarital relationships. Journal of Social and Personal Relationships, 10, 39-53.

Rubin, D. B. (1976). Inference and missing data. Biometrika, 63, 581-592.

Rusbult, C. R., Verette, J., Whitney, G. A., Slovik, L. F., \& Lipkus, I. (1991). Accommodation processes in close relationships: Theory and preliminary evidence. Journal of Personality and Social Psychology, 60, 53-78.

Schafer, J. L. (1997). Analysis of incomplete multivariate data. London, England: Chapman \& Hall.

Shariff, A. F., \& Norenzayan, A. (2007). God is watching you: Priming God concepts increases prosocial behavior in an anonymous economic game. Psychological Science, 9, 803-809.

Smith, T. W. (1994). Attitudes towards sexual permissiveness: Trends, correlates, and behavioral connections. In A. S. Rossi (Ed.), Sexuality across the life course (pp. 63-97). Chicago, IL: University of Chicago Press.

Stanley, S. M., \& Markman, H. J. (1992). Assessing commitment in personal relationships. Journal of Marriage and the Family, 54, 595608 .

Stone, A. A., Turkhan, J. S., Bachrach, C. A., Jobe, J. B., Kurtzman, H. S., \& Cain, V. S. (2000). The science of self-report. Implications for research and practice. Mahwah, NJ: Erlbaum.

Symons, D. (1979). The evolution of human sexuality. New York, NY: Oxford University Press.

Taylor, R. J., Chatters, L. M., \& Levin, J. S. (2004). Religion in the lives of African Americans: Social, psychological, and health perspectives. Thousand Oaks, CA: Sage.

Tesser, A., Martin, L., \& Mendolia, M. (1995). The impact of thought on attitude extremity and attitude-behavior consistency. In R. E. Petty \& J. A. Krosnick (Eds.), Attitude strength: Antecedents and consequences (pp. 73-92). Hillsdale, NJ: Erlbaum.

Townsend, M., Kladder, V., Ayele, H., \& Mulligan, T. (2002). Systematic review of clinical trials examining the effects of religion on health. Southern Medical Journal, 95, 1429-1434.

U.S. Religious Landscape Survey. (2008). Retrieved July 30, 2008, from http://religions.pewforum.org/pdf/report2religious-landscape-study-keyfindings.pdf

Wiederman, M. W. (1997). Extramarital sex: Prevalence and correlates in a national survey. Journal of Sex Research, 34, 167-174.

Wiederman, M. W., \& Hurd, C. (1999). Extradyadic involvement during dating. Journal of Social and Personal Relationships, 16, 265-274.

Wile, D. B. (1993). After the fight: A night in the life of a couple. New York, NY: Guilford.

Wrzesniewski, A., McCauley, C. R., Rozin, P., \& Schwartz, B. (1997). Jobs, careers, and callings: People's relations to their work. Journal of Research in Personality, 31, 21-33.

Received May 7, 2009

Revision received March 3, 2010

Accepted March 10, 2010 


\section{Correction to Fincham, Lambert, and Beach (2010)}

The article "Faith and Unfaithfulness: Can Praying for Your Partner Reduce Infidelity?" by Frank D. Fincham, Nathaniel M. Lambert, and Steven R. H. Beach (Journal of Personality and Social Psychology, 2010, Vol. 99, No. 4, pp. 649-659) contained an error in Table 2. The third column table heading Undirected prayer should have read Partner positive.

DOI: $10.1037 / \mathrm{a} 0021541$ 